\title{
Laryngopharyngeal Reflux: Symptoms, Signs, and Presence of Pepsin in Saliva - A Reliable Diagnostic Triad
}

\author{
Shilpa Divakaran ${ }^{10}$ Sivaa Rajendran ${ }^{20}$ Roshan Marie Thomas ${ }^{3(0)}$ Jaise Jacob$^{2(0)}$ Mary Kurien ${ }^{2(1)}$
}

${ }^{1}$ Department of ENT, NMC Specialty Hospital, Muscat, Oman

${ }^{2}$ Department of Biochemistry, Pondicherry Institute of Medical Sciences, Kalapet, Puducherry, India

${ }^{3}$ Department of ENT, City Hospital , Kochi, Kerala, India
Address for correspondence Shilpa Divakaran, MS ENT, MRCS Edin (ENT), Specialty Doctor, Department of ENT, Sandwell and West Birmingham NHS trust, Dudley Road, Birmingham, United Kingdom (e-mail: dr.d.shilpa@gmail.com).

Int Arch Otorhinolaryngol 2021;25(2):e273-e278.

Abstract

Keywords
- reflux findings score
- reflux symptoms
index
- saliva
- pepsin
- laryngopharyngeal
reflux

Introduction Twenty-four-hour multichannel intraluminal impedance with double probe $\mathrm{pH}$ monitoring (MII-pH), though considered the most sensitive tool for the diagnosis of gastroesophageal reflux disease (GERD), is invasive, time consuming, not widely available, and unable to detect non-acid reflux. In contrast, the presence of pepsin in the saliva would act as a marker for reflux, considering that pepsin is only produced in the stomach.

Objective To evaluate the predictive value of salivary pepsin in diagnosing laryngopharyngeal reflux (LPR) as suggested by the results of reflux symptom index (RSI > 13), reflux finding score (RFS $>7$ ), and positive response to treatment with a 4-week course of proton-pump inhibitors.

Methods This prospective study was done at a tertiary care hospital on 120 adult patients attending ENT OPD with clinical diagnosis of LPR. The presence of pepsin in their pharyngeal secretions and saliva using a lateral flow device, the Peptest, was compared with RSI, RFS, and with the response to medical treatment using the Chi-squared test.

Results Salivary pepsin was found to be positive in $68 \%$ of the patients, with $87.5 \%$ of them showing positive response to treatment. Chi-squared analysis showed a significant association between positive salivary pepsin and RFS $>7, \mathrm{RSI}>13$, a combination of RFS $>7$ and RSI $>13$ as well as with response to treatment $(p<0.0001)$.

Conclusion When considered along with the clinical indicators of RFS and RSI of more than 7 and 13, respectively, and/or with a response to treatment, a positive salivary pepsin test indicates statistically significant chance of presence of LPR.

\section{Introduction}

Gastroesophageal reflux disease (GERD) is defined as the retrograde flow of gastric contents into the esophagus or above. Laryngopharyngeal reflux (LPR) is the condition aris- ing from the retrograde flow of gastric contents into the larynx/pharynx, thus causing tissue damage that results in a wide array of clinical symptoms and signs. Though LPR and GERD are an extension of similar diseases, they differ considerably in the pathophysiology, clinical presentation, received

October 27, 2019

accepted

March 4, 2020

published online

June 30,2020
DOI https://doi.org/ 10.1055/s-0040-1709987. ISSN 1809-9777.

\footnotetext{
(c) 2020. Fundação Otorrinolaringologia. All rights reserved. This is an open access article published by Thieme under the terms of the Creative Commons Attribution-NonDerivative-NonCommercial-License, permitting copying and reproduction so long as the original work is given appropriate credit. Contents may not be used for commercial purposes, or adapted, remixed, transformed or built upon. (https://creativecommons.org/ licenses/by-nc-nd/4.0/) Thieme Revinter Publicações Ltda., Rua do Matoso 170, Rio de Janeiro, RJ, CEP 20270-135, Brazil
} 
diagnosis, and treatment. Gastroesophageal reflux disease is said to occur due to dysfunction of the lower esophageal sphincter whereas in LPR, the upper esophageal sphincter is at fault. The main symptom of GERD is heartburn due to esophagitis. In LPR, only $25 \%$ of the patients have esophagitis, and around $40 \%$ complain of heartburn. ${ }^{1}$

The major symptoms of LPR are globus sensation, throat irritation, dysphagia, frequent throat clearing, dryness of throat, chronic cough, hoarseness of voice, and voice fatigue. These symptoms are long-term and cause intermittent concern to the patient. If severe, there can be vocal fold/ subglottic edema andendolaryngeal mucus/granuloma formation. ${ }^{2}$ It has been shown that mixed as well as non-acid reflux contribute to most of the symptoms of LPR as compared with purely acid reflux, in the case of GERD. ${ }^{3}$ Pepsin is an enzyme in gastric juice that has been implicated in the pathogenesis of LPR as it can damage the laryngeal mucosa, even at mild acidic or alkaline $\mathrm{pH}^{4-6}$

The diagnosis of LPR based on symptoms and laryngeal findings alone has poor sensitivity and specificity as most of the abnormal findings are also seen in around $86 \%$ of healthy individuals. ${ }^{7}$ The mainstay of the diagnosis of LPR at present is a combination of symptoms, fiberoptic endoscopic findings, and 24-hour multichannel intraluminal impedance (MII) combined with double-probe $\mathrm{pH}$ monitoring (MII-pH). Multichannel intraluminal impedance-pH monitoring is now considered the most sensitive tool for the diagnosis and characterization of GERD and its laryngopharyngeal symptoms. It detects both acid and non-acid gastric reflux and assesses the proximal extent and nature of refluxate. However, MII-pH monitoring is invasive, time consuming and not available in many centers, with additional patient intolerability. ${ }^{8-11}$ Moreover, non-acid reflux cannot be detected by $\mathrm{pH}$ monitoring alone. Recent insight into the pathophysiology of LPR with the help of MII-pH studies has demonstrated non-acid and mixed reflux to be more common than acid reflux. ${ }^{3}$ Pepsin plays a major role in the pathogenesis of LPR. Pepsin can damage the laryngeal and pharyngeal mucosa at both acidic and alkaline $\mathrm{pH}$, as it shows some activity even at $\mathrm{pH} 8 .^{12}$ Johnston et al did a prospective translational study in established porcine in vitro model to examine the effect of active/inactive pepsin on laryngeal CAIII and Sep70 protein levels. They reported detectable levels of pepsin in laryngeal epithelia after a reflux event. ${ }^{12}$ Normally, pepsin in this site would be enzymatically inactive, as the mean $\mathrm{pH}$ of the laryngopharynx is 6.8. Significantly, pepsin would be reactivated by a subsequent decrease in $\mathrm{pH}$, such as would occur during an acidic reflux event or possibly after uptake into intracellular compartments of lower $\mathrm{pH}$. Since pepsin is produced only in the stomach, its presence in the saliva would act as a marker for reflux. ${ }^{13}$ Pepsin, thus, has the potential to overcome the invasive,time-consuming,and expensive MII-pH studies, as it can be easily detected in the pharyngeal secretions and saliva using a lateral flow device such a Peptest.

There is a paucity of reports from the Indian subcontinent on this easily available, relatively less expensive, less timeconsuming and non-invasive test utilizing salivary pepsin in the diagnosis of LPR. Hence, this study was undertaken.

\section{Materials and Methods}

This prospective study was performed at a tertiary care hospital following institutional research and ethical committee approval (No. RC/16/142). The objective of the present study was to evaluate the diagnostic value of pepsin in saliva in the diagnosis of LPR. Written informed consent was obtained from all patients. All adult patients attending the ear, nose and throat outpatient department with a history of change in voice/ burning sensation in the substernal or epigastric region/regurgitation/dysphagia/throat pain/cough/foreign body sensation in throat/frequent throat clearing for more than 4 weeks with clinical diagnosis of LPR were selected for the study. They were then asked to complete a questionnaire with various possible symptoms suggestive of LPR for calculating reflux symptom index (RSI). The RSI is a 9-point questionnaire, each rated on a Likert scale from 0 to 5 ,considering a score $>13$ suggestive of $\mathrm{LPR}^{8}$ All patients then underwent flexible nasopharyngolaryngoscopy for assessing reflux findings score (RFS), which is an 8-component assessment tool for quantifying thevseverity of laryngeal inflammation. An RFS score $>7$ is suggestive of LPR. ${ }^{9}$ Those with previous laryngeal surgery, neoplasm of the pharynx and larynx, chronic granulomatous lesion of the larynx/ pharynx, and use of proton pump inhibitors in the previous month were excluded.

Saliva samples were collected 1 hour after meals. Patients were instructed to cough up saliva from the back of their throat and spit into $30-\mathrm{ml}$ standard tubes containing $0.5 \mathrm{~mL}$ of $0.01 \mathrm{~mol} / \mathrm{L}$ citric acid at $\mathrm{pH} 2.5$ to preserve the action of any pepsin present. The samples were refrigerated at $4^{\circ} \mathrm{C}$. Immunoserologic pepsin analysis was performed within a week of collecting the sample, using a Peptest lateral flow device (LFD) (RD Biomed Ltd, Hull, UK) by one of the coinvestigators who was blinded to the clinical data. The collection tubes were centrifuged at 4,000 rpm for 5 minutes. Eighty $\mu \mathrm{L}$ of the supernatant were drawn up using standard micropipettes and transferred to a clear screwtop microtube containing $240 \mu \mathrm{L}$ of migration buffer solution. This tube was mixed with a vortex mixer for 10 seconds. Using a dual bulb pipette, $80 \mu \mathrm{L}$ of this sample was placed in the well of the lateral flow device (LFD). The control line appeared within a few minutes and the test line appeared within 5 to 15 minutes if the result was positive.

All patients were given proton pump inhibitor (PPI - esomeprazole $40 \mathrm{mg}$ twice a day) and prokinetic (domperidone $10 \mathrm{mg}$ twice a day) for 4 weeks and the response to treatment was assessed with RSI reduction by $50 \%$. The patients were divided into 3 groups for analysis and response to treatment group A (with RFS $>7$ ); Group B (RFS $>7$ and RSI $>13$ ); Group C

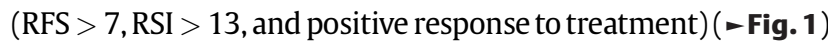

\section{Results}

A total of 120 patients were recruited for the study, of which there were 53 men and 67 women. The age range was from 21 to 68 , with the average age being 40 years. The average age was 39 in those with positive salivary pepsin and 43 in those with a negative test. The most common symptoms were throat irritation (58.3\%), globus sensation (46\%), dry cough (24\%), 
Patients with symptoms suggestive of LPR for $>4$ weeks, consenting to the study $(n=120)$

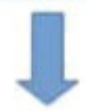

Questionnaire for RSI ,

Flexible nasopharyngolaryngoscopy for RFS

\section{Saliva sample taken and tested for pepsin with PEPTEST \\ Medication given for a month}

Patients divided into 3 groups for analysis
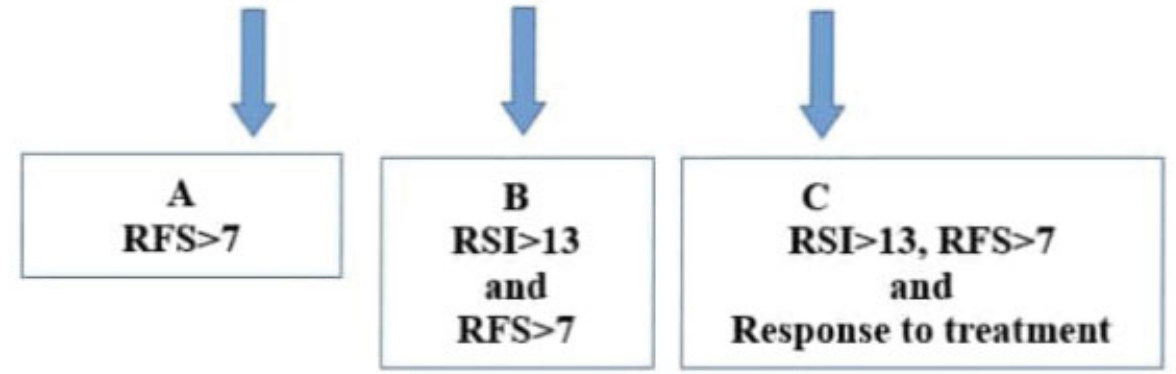

Fig. 1 Flowchart showing study procedures.

Table 1 Comparison of general characteristics of pepsinpositive and pepsin-negative groups

\begin{tabular}{|c|c|c|}
\hline Characteristic & Pepsin $(+)$ & Pepsin (-) \\
\hline Age & 39 & 43 \\
\hline Men & $29(55 \%)$ & 24 (45\%) \\
\hline Women & $44(66 \%)$ & $23(34 \%)$ \\
\hline Mean RSI & 16.61 & 12.14 \\
\hline Mean RFS & 9.01 & 7.89 \\
\hline $\begin{array}{l}\text { Mean RSI after } \\
\text { treatment }\end{array}$ & 10.34 & 9.53 \\
\hline $\begin{array}{l}\text { Response to } \\
\text { treatment }\end{array}$ & 54 (45\%) & 19 (16\%) \\
\hline \multirow[t]{2}{*}{$\begin{array}{l}\text { Most common } \\
\text { item in RSI }\end{array}$} & $\begin{array}{l}\text { Globus } \\
\text { sensation } \\
(54 \%)\end{array}$ & $\begin{array}{l}\text { Globus } \\
\text { sensation } \\
(38 \%)\end{array}$ \\
\hline & $\begin{array}{l}\text { Excess throat } \\
\text { mucus (23\%) }\end{array}$ & $\begin{array}{l}\text { Dry cough } \\
(18 \%)\end{array}$ \\
\hline \multirow[t]{2}{*}{$\begin{array}{l}\text { Most common } \\
\text { sign in RFS }\end{array}$} & $\begin{array}{l}\text { Arytenoid } \\
\text { congestion } \\
(67 \%)\end{array}$ & $\begin{array}{l}\text { Arytenoid } \\
\text { congestion } \\
(47 \%)\end{array}$ \\
\hline & $\begin{array}{l}\text { Thick } \\
\text { endolaryngeal } \\
\text { mucus (34\%) }\end{array}$ & $\begin{array}{l}\text { Vocal cord } \\
\text { erythema } \\
(26 \%)\end{array}$ \\
\hline
\end{tabular}

Abbreviations: RFS, reflux finding score; RSI, reflux symptom index. and regurgitation (15\%). The mean RSI was 14.86 overall, 16.61 in the pepsin-positive, and 12.14 in the pepsin-negative patients. The mean RFS was 8.53 overall, 9.01 in the pepsinpositive, and 7.89 in the pepsin-negative patients. The general characteristic of both groups (pepsin-positive and negative) are shown in - Table 1.

Of the 120 participants who enrolled in the study, 97 (80.8\%) had RFS $>7$, and 72 (60\%) had RSI > 13. On combining these two parameters, there were a total of 68 (56.7\%) participants who had both RFS $>7$ and RSI $>13$, whereas only 19 (15.8\%) had both RFS and RSI below this cut off. Salivary pepsin was found to be positive in 82 of the 120 subjects (68.1\%). Seventy-two of the patients showed a positive response to the treatment, of which 63 had a positive Peptest, whereas 48 participants showed no response to the treatment,29 of whom tested negative for pepsin ( - Tables 2 \& 3).

The chi-squared analysis showed a significant association between positive salivary pepsin and RFS $>7$ as well as with RSI $>13$. Similarly, positive associations were observed for positive pepsin and a combination of RFS $>7$ and RSI $>13$ alone as well as with response to treatment ( - Table 4 ).

\section{Discussion}

Laryngopharyngeal reflux has become a highly prevalent condition, causing considerable concern both for the patient 
Table 2 Distribution of different groups based on salivary pepsin

\begin{tabular}{|l|l|l|}
\hline Group & Pepsin + & Pepsin - \\
\hline RFS $>7$ & 74 & 23 \\
\hline RFS $<7$ & 8 & 15 \\
\hline RSI $>13$ & 68 & 4 \\
\hline RSI $<13$ & 14 & 34 \\
\hline RFS $>7$ \& RSI $>13$ & 65 & 3 \\
\hline RFS $<7 \&$ RSI $<13$ & 5 & 14 \\
\hline Positive Response to treatment & 63 & 9 \\
\hline No Response to treatment & 19 & 29 \\
\hline $\begin{array}{l}\text { RFS }>7 \text { \& RSI }>13 \& \text { positive } \\
\text { response to treatment }\end{array}$ & 56 & 1 \\
\hline
\end{tabular}

Abbreviations: RFS, reflux finding score; RSI, reflux symptom index. and the otolaryngologist. ${ }^{10}$ It presents a diagnostic challenge owing to atypical presentation and lack of readily available sensitive diagnostic tests. More often than not, the treatment is started empirically with PPIs. In a common clinical setting, LPR is diagnosed based on symptoms and laryngoscopic findings. Reflux symptom score (RSI) is a commonly used tool, which helps in keeping a record of symptoms for reassessment after treatment. An RSI score $>13$ is highly suggestive of LPR. ${ }^{9}$ In our study, the mean RSI score was 14.86 (overall), which showed improvement with treatment in 60\% of patients ( - Table $\mathbf{1}$ ).

Several studies have been conducted evaluating pepsin as a marker for LPR, all of them showing considerable variation in the sensitivity and specificity of Peptest. A cross-sectional study conducted by Ocak e al, ${ }^{14}$ in which a two-channeled 24-hour esophageal $\mathrm{pH}$ monitoring catheter was placed in 20 patients with a suspicion of LPR, and each patient gave one sample of sputum for the immunoserologic pepsin detection

Table 3 Latent class distribution

\begin{tabular}{|l|l|l|l|l|l|l|}
\hline Group & RFS $>\mathbf{7}$ & RSI $>13$ & RESPONSE + & PEPSIN + & FREQ & CUMULATIVE FREQ \\
\hline 1 & + & - & - & - & 15 & 15 \\
\hline 2 & - & + & - & - & 1 & 16 \\
\hline 3 & - & - & + & - & 2 & 18 \\
\hline 4 & - & - & - & + & 5 & 23 \\
\hline 5 & + & + & - & - & 2 & 25 \\
\hline 6 & + & - & + & - & 5 & 30 \\
\hline 7 & + & - & - & + & 5 & 35 \\
\hline 8 & - & + & + & - & 0 & 35 \\
\hline 9 & - & + & - & + & 0 & 35 \\
\hline 10 & - & - & + & + & 0 & 35 \\
\hline 11 & + & + & + & - & 1 & 36 \\
\hline 12 & + & + & - & - & 9 & 45 \\
\hline 13 & + & - & + & + & 4 & 49 \\
\hline 14 & - & + & + & + & 3 & 52 \\
\hline 15 & + & + & + & + & 56 & 108 \\
\hline 16 & - & - & - & - & 12 & 120 \\
\hline
\end{tabular}

Abbreviations: FREQ, frequency; RFS, reflux finding score; RSI, reflux symptom index.

Table 4 Chi-squared analysis between positive pepsin and the various clinical parameters

\begin{tabular}{|c|c|c|c|c|c|c|c|c|}
\hline & \multicolumn{2}{|l|}{$\begin{array}{l}\text { RFS >7 } \\
\mathrm{N}(\%)\end{array}$} & \multicolumn{2}{|l|}{$\begin{array}{l}\mathrm{RSI}>13 \\
\mathrm{~N}(\%)\end{array}$} & \multicolumn{2}{|c|}{$\begin{array}{l}\text { RFS > } 7 \& \text { RSI }>13 \\
N(\%)\end{array}$} & \multicolumn{2}{|c|}{$\begin{array}{l}\mathrm{RFS}>7 \& \mathrm{RSI}>13 \& \\
\text { positive response to } \\
\text { treatment } \\
\mathrm{N}(\%)\end{array}$} \\
\hline & YES & NO & YES & NO & YES & NO & YES & NO \\
\hline PEPSIN + & $74(76.3)$ & $8(34.7)$ & $68(94.4)$ & $14(29.2)$ & 65 (95.6) & $5(26.3)$ & $56(98.2)$ & $5(29.4)$ \\
\hline PEPSIN - & $23(23.7)$ & $15(65.3)$ & $4(5.6)$ & $34(70.8)$ & $3(4.4)$ & $14(73.7)$ & $1(1.8)$ & $12(70.6)$ \\
\hline TOTAL & 97 & 23 & 72 & 48 & 68 & 19 & 57 & 17 \\
\hline Chi-squared statistic ( $p$ Value) & \multicolumn{2}{|c|}{$\begin{array}{l}14.8 \\
(<0.00019)\end{array}$} & \multicolumn{2}{|c|}{$\begin{array}{l}56.7 \\
(<\mathbf{0 . 0 0 0 1 )}\end{array}$} & \multicolumn{2}{|l|}{$\begin{array}{l}45.3 \\
(<\mathbf{0 . 0 0 0 1 )}\end{array}$} & \multicolumn{2}{|c|}{$\begin{array}{l}42.8 \\
(<0.0001)\end{array}$} \\
\hline
\end{tabular}

Abbreviations: RFS, reflux finding score; RSI, reflux symptom index. 
test. This test was noted to have a sensitivity of $30 \%$ and a specificity of $100 \%$, with a positive predictive value of $100 \%$. The low sensitivity was attributed to single sample collection. In addition, this study also noted the proximal probe of the pepsin positive patients having an apparent acidic $\mathrm{pH}$ as compared with the pepsin-negative group ( $\mathrm{pH}: 3.26$ versus $\mathrm{pH}$ : 6). They thus suggest that a positive pepsin test in a patient clinically suspected to have LPR can be a cost-effective, accurate, and alternative diagnostic method. ${ }^{12}$ Another study by Alexander et al $^{15}$ suggests that salivary pepsin has a sensitivity of $78 \%$ and specificity of $53 \%$ for predicting an RFS $>7$. Wang et al $^{16}$ conducted a meta-analysis to assess the diagnostic value of pepsin in saliva for LPR. The pooled sensitivity and specificity were $64 \%$ and $68 \%$, respectively. They concluded that salivary pepsin has moderate value in diagnosing LPR and requires further studies to optimize the method of detection of pepsin. The reason for such varied results across various studies could be differences in sample size, number of salivary samples collected, timing of sample collection, method of pepsin detection and criteria for diagnosis of LPR. As there is a wide range of concentration of salivary pepsin observed in an individual over a period of 24 hours, samples collected soon after reflux event are more likely to be positive. ${ }^{16}$ In our study, 82 patients (68.1\%) were positive for salivary pepsin. Similar results were observed in a study by Ianella et al to assess the correlation between obstructive sleep apnea (OSA) and LPR, where salivary pepsin was used to confirm the diagnosis of clinically suspected LPR based on positive RSI \& RFS. $66.6 \%$ of the patients with clinical LPR tested positive for salivary pepsin. ${ }^{17}$

There are a few studies comparing treatment response to salivary pepsin, but none have studied the correlation between pepsin and combined RSI, RFS, and a positive response to treatment. A study by Wang et al noted significant association between strongly positive salivary pepsin and a good treatment response. ${ }^{18}$ Another study by Alexander et al showed significant correlation between RFS scores and positive Peptest, but no correlation between RSI and a positive Pepstest. ${ }^{15}$ Sereg-Bahar et al studied pepsin and bile acids in the saliva of patients with LPR and reported a significant correlation between the RSI and RFS scores and the level of total pepsin and bile acids in the saliva. ${ }^{19}$ There was a significant association between a positive Peptest and RSI $>13$ and RFS $>7$, individually, as well as on combining RSI and RFS together. The association was significant even when combining RFS, RSI and response to treatment $(p<$ 0.05 ), in our study (-Table 4), making our study the first to compare associations between these parameters together.

This prospective study indicates that salivary pepsin test is indeed a very useful test in the diagnosis of LPR, especially in a set up in which MII-pH is not available. A positive pepsin test in combination with RSI, RFS and trial of response to treatment revealed significant association.

\section{Conclusion}

In the clinical presentation of a constellation of symptoms and signs in LPR, RSI)and RFS)are to be considered. The present prospective study of immunoserologic pepsin analysis in the saliva of patients revealed that a positive salivary pepsin test along with RSI $>7$, RFS $>13$, and positive response to treatment with PPIs indicates statistically significant chance of presence of LPR. Hence, salivary pepsin test, a relatively inexpensive, less time-consuming and patient friendly non-invasive test is being suggested as part of armamentarium in the diagnosis of LPR.

\section{Limitations}

The diagnosis of LPR could not be confirmed with MII-pH due to non-availability of the equipment.

Only a single sample of saliva was tested. The number of positives may have been more if there were multiple samples. However, multiple samples could not be obtained due to limited funds. There was a lack of control group.

\section{Funding}

The present study was possible with internal funding provided by the research committee of the Pondicherry Institute of Medical Sciences, Puducherry, India.

Conflict of Interests

The authors have no conflict of interests to declare.

\section{References}

1 Koufman JA. The otolaryngologic manifestations of gastroesophageal reflux disease (GERD): a clinical investigation of 225 patients using ambulatory 24 -hour $\mathrm{pH}$ monitoring and an experimental investigation of the role of acid and pepsin in the development of laryngeal injury. Laryngoscope 1991;101(4 Pt 2, Suppl 53):1-78

2 Koufman JA, Aviv JE, Casiano RR, Shaw GY. Laryngopharyngeal reflux: position statement of the committee on speech, voice, and swallowing disorders of the American Academy of Otolaryngology-Head and Neck Surgery. Otolaryngol Head Neck Surg 2002;127 (01):32-35

3 Lee JS, Jung AR, Park JM, Park MJ, Lee YC, Eun YG. Comparison of Characteristics According to Reflux Type in Patients With Laryngopharyngeal Reflux. Clin Exp Otorhinolaryngol 2018;11(02): 141-145

4 Bulmer DM, Ali MS, Brownlee IA, Dettmar PW, Pearson JP. Laryngeal mucosa: its susceptibility to damage by acid and pepsin. Laryngoscope 2010;120(04):777-782

5 Jiang A, Liang M, Su Z, et al. Immunohistochemical detection of pepsin in laryngeal mucosa for diagnosing laryngopharyngeal reflux. Laryngoscope 2011;121(07):1426-1430

6 Hicks DM, Ours TM, Abelson TI, Vaezi MF, Richter JE. The prevalence of hypopharynx findings associated with gastroesophageal reflux in normal volunteers. J Voice 2002;16(04):564-579

7 Hila A, Agrawal A, Castell DO. Combined multichannel intraluminal impedance and $\mathrm{pH}$ esophageal testing compared to $\mathrm{pH}$ alone for diagnosing both acid and weakly acidic gastroesophageal reflux. Clin Gastroenterol Hepatol 2007;5(02):172-177

8 Belafsky PC, Postma GN, Koufman JA. Validity and reliability of the reflux symptom index (RSI). J Voice 2002;16(02):274-277

9 Belafsky PC, Postma GN, Koufman JA. The validity and reliability of the reflux finding score (RFS). Laryngoscope 2001;111(08):1313-1317

10 Altman KW, Stephens RM, Lyttle CS, Weiss KB. Changing impact of gastroesophageal reflux in medical and otolaryngology practice. Laryngoscope 2005;115(07):1145-1153 
11 Knight J, Lively MO, Johnston N, Dettmar PW, Koufman JA. Sensitive pepsin immunoassay for detection of laryngopharyngeal reflux. Laryngoscope 2005;115(08):1473-1478

12 Johnston N, Dettmar PW, Bishwokarma B, Lively MO, Koufman JA. Activity/stability of human pepsin: implications for reflux attributed laryngeal disease. Laryngoscope 2007;117(06):1036-1039

13 Bardhan KD, Strugala V, Dettmar PW. Reflux revisited: advancing the role of pepsin. Int J Otolaryngol 2012;2012:646901. Doi: 10.1155/ 2012/646901

14 Ocak E, Kubat G, Yorulmaz İ. Immunoserologic pepsin detection in the saliva as a non-invasive rapid diagnostic test for laryngopharyngeal reflux. Balkan Med J 2015;32(01):46-50

15 Spyridoulias A, Lillie S, Vyas A, Fowler SJ. Detecting laryngopharyngeal reflux in patients with upper airways symptoms: Symptoms, signs or salivary pepsin? Respir Med 2015;109(08):963-969
16 Wang J, Zhao Y, Ren J, Xu Y. Pepsin in saliva as a diagnostic biomarker in laryngopharyngeal reflux: a meta-analysis. Eur Arch Otorhinolaryngol 2018;275(03):671-678

17 Iannella G, Vicini C, Polimeni A, et al. Laryngopharyngeal Reflux Diagnosis in Obstructive Sleep Apnea Patients Using the Pepsin Salivary Test. Int J Environ Res Public Health 2019; 16(11):2056

18 Wang CP, Wang CC, Lien HC, et al. Saliva Pepsin Detection and Proton Pump Inhibitor Response in Suspected Laryngopharyngeal Reflux. Laryngoscope 2019;129(03):709-714

19 Sereg-Bahar M, Jerin A, Jansa R, Stabuc B, Hocevar-Boltezar I, Sereg-Bahar M. Pepsin and bile acids in saliva in patients with laryngopharyngeal reflux - a prospective comparative study. Clin Otolaryngol 2015;40(03):234-239 